\title{
Finite-Time Adaptive Higher-Order SMC for the Nonlinear Five DOF Active Magnetic Bearing System
}

\author{
Sudipta Saha ${ }^{1,+(\mathbb{D}}$, Syed Muhammad Amrr ${ }^{1, *,+} \mathbb{D}$, Abdelaziz Salah Saidi ${ }^{2,3} \mathbb{D}$, Arunava Banerjee ${ }^{1} \mathbb{D}$ \\ and M. Nabi ${ }^{1}$ (D)
}

1 Department of Electrical Engineering, Indian Institute of Technology Delhi, New Delhi 110016, India; sudi.saha009@gmail.com (S.S.); arunavabanerjee27@gmail.com (A.B.); mnabi@ee.iitd.ac.in (M.N.)

2 Department of Electrical Engineering, King Khalid University, Abha 61411, Saudi Arabia; asaidi@kku.edu.sa

3 Laboratoire des Systèmes Electriques, Ecole Nationale d'Ingénieurs de Tunis, Université de Tunis El Manar, Tunis 1002, Tunisia

* Correspondence: syedamrr@gmail.com

+ These authors have contributed equally to this work.

check for

updates

Citation: Saha, S.; Amrr, S.M.; Saidi, A.S.; Banerjee, A.; Nabi, M. Finite-Time Adaptive Higher-Order SMC for the Nonlinear Five DOF Active Magnetic Bearing System. Electronics 2021, 10, 1333. https:/ / dx.doi.org/10.3390/electronics10111333

Academic Editors: Ciprian Lupu, Dumitru Popescu, Haoping Wang and Severus C. Olteanu

Received: 12 April 2021

Accepted: 28 May 2021

Published: 1 June 2021

Publisher's Note: MDPI stays neutral with regard to jurisdictional claims in published maps and institutional affiliations.

Copyright: (c) 2021 by the authors. Licensee MDPI, Basel, Switzerland. This article is an open access article distributed under the terms and conditions of the Creative Commons Attribution (CC BY) license (https:/ / creativecommons.org/licenses/by/ $4.0 /)$.

\begin{abstract}
The active magnetic bearings (AMB) play an essential role in supporting the shaft of fast rotating machines and controlling the displacements in the rotors due to the deviation in the shaft. In this paper, an adaptive integral third-order sliding mode control (AITOSMC) is proposed. The controller suppresses the deviations in the rotor and rejects the system uncertainties and unknown disturbances present in the five DOF AMB system. The application of AITOSMC alleviates the problem of high-frequency switching called chattering, which would otherwise restrict the practical application of sliding mode control (SMC). Moreover, adaptive laws are also incorporated in the proposed approach for estimating the controller gains. Further, it also prevents the problem of overestimation and avoids the use of a priori assumption about the upper bound knowledge of total disturbance. The Lyapunov and homogeneity theories are exploited for the stability proof, which guarantees the finite-time convergence of closed-loop and output signals. The numerical analysis of the proposed strategy illustrates the effective performance. Furthermore, the comparative analysis with the existing control schemes demonstrates the efficacy of the proposed controller.
\end{abstract}

Keywords: stabilization control; sliding mode control; adaptive gain estimation; finite-time theory; homogeneity theory

\section{Introduction}

Often the rotating machines suffer from rotor anomaly, which is mainly due to the unwanted forces (electromagnetic and exogenous disturbance), system parametric uncertainties, coupling, and gyroscopic effects. Active magnetic bearings (AMB) are used for regulating the rotor dynamics and providing active vibration control using electromagnetic forces through an appropriate feedback control law. Traditional mechanical bearings were used in the rotating machines where it supports the rotating shaft with physical contact or with the help of fluid. The use of AMBs are preferred over traditional mechanical bearings in high speed applications due to the advancements in power electronics and embedded systems, which has enhanced the overall computational capabilities of a system. The AMB systems have the following advantages over conventional bearings [1]: (1) high-speed rotation, (2) reduced friction losses, (3) less energy utilization, (4) reduced vibration or noise, (5) higher longevity, among others [2,3]. Moreover, the five degree of freedom (DOF) structure based AMB systems are also employed in various electro-mechanical applications, such as turbo-molecular pumps [4], turbo-expander [5], high-speed flywheel rotor system [6], and bearingless induction motor [7]. The AMB system has also been used for machining applications [8], medical instruments (blood pumps) [9], high temperature applications [10], aerospace industry [11], combat vehicles [12], transportation industry [13], etc. 
In the last few decades, extensive research has been conducted for controller design of the AMB system. Nonlinear control methods have been used which devices a control structure allowing control of bearingless motor featuring significant nonlinear current to force/torque relationship in [14]. The classical control method of PID has been applied for the position control of the AMB system [15] and most industrial AMBs are still controlled by PID controllers. A combination of frequency and time domain based optimization procedure is discussed in [16], which enhances the performance of the overall system using AMB controlled through PID controller and an experimental validation is also provided. Further, an advanced PID based control is presented in [17,18], where the gains of the PID are updated based on a set of rules. However, the PID control has low robustness abilities against model uncertainties, disturbances, and noise. The effect of noise and disturbances in the PID based control system can be minimized with the use of filters, such as lead, notch, and low pass filters [19]. Further, tuning of the PID gains are critical to the performance of the whole system and thus inefficient design of these parameters may compromise the transient response, such as settling time, overshoots, and oscillations. Along with PID controller, model based advanced control strategies are also widely used for efficiently controlling the performance of AMBs which include: an adaptive multiinput multi-output (MIMO) pole placement method for the control commissioning of an AMB-supported rotor system [20], linear quadratic regulator for an AMB based flexible rotor virtual collocated system [21], $\mathcal{H}_{\infty}$ controller design for AMBs considering nonlinear vibrational rotor dynamics [22], among others. Recently, an optimal control technique called pseudo-spectral method has been employed [23] for the regulation of a nonlinear AMB model. However, uncertainties and vibrations were not considered while designing the proposed controller.

As mentioned earlier, the AMB system is subjected to harmonic disturbances, rotor deviations, etc., thus, it requires the use of advanced robust control strategies. A widely used disturbance rejection control method is the sliding mode control (SMC) approach [24-27]. The SMC for an AMB system has been previously explored in [28-30]. The authors of [28] have designed a linear SMC to retain the elevation in the air gap, while an integral SMC (ISMC) with the neural network-based gain update is employed for the regulation of the AMB system with 5 degree of freedom (DOF) in [29]. Further, in [30], a deep convolution neural network based SMC is proposed for the regulation of 5 DOF AMB system. However, under these SMC techniques, the problem of high-frequency chattering [31,32] have not been addressed. The main reason for the occurrence of chattering in the input of SMC is the utilization of discontinuous high frequency switching function (i.e., $\operatorname{signum}(s)$, where $s$ is the sliding surface) to cancel the effect of disturbances. The presence of chattering component in the system can excite the unmodeled fast dynamics and create undesired oscillations, which in turn can degrade the stability of the system. The discontinuous high frequency perturbation can also causes wear and tear in the actuator which may lead to the possibility of system destabilization or even destruction of the plant [33-35]. Furthermore, the aforementioned papers have reported only the asymptotic stability which is less comprehensive in terms of theoretical stability analysis.

There are few methods to reduce or alleviate the chattering from the SMC input such as boundary layer technique [36,37], disturbance observers [38-40] and higher-order SMC (HOSMC) [37,41,42]. In the boundary layer technique, continuous approximation of signum function is performed by introducing a boundary of small width $(\phi)$ around $s=0$ and replacing the signum(s) with a saturation function. As a result, $s$ becomes continuous within $|s|<\phi$ and out side of this boundary, the saturation function behaves like the signum function. The following expression defines the saturation function:

$$
\operatorname{sat}(s / \phi)= \begin{cases}\operatorname{signum}(s / \phi) & \text { if }|s / \phi| \geq 1 \\ s / \phi & \text { if }|s / \phi|<1\end{cases}
$$


However, the drawback of this approach is that the sliding mode loses the robustness against uncertainties when $s$ reaches inside the boundary layer. This approach is sensitive to the fast unmodeled dynamics and may result in unsatisfactory performance $[36,43]$. Besides, the problem of steady state error also exists in this technique, and is directly proportional to the width of the layer. Therefore, in this approach a trade-off has to be made between the chattering behavior attenuation and performance accuracy [44]. Another way in which the undesirable phenomenon of chattering can be reduced is through the use of disturbance error in combination with the SMC where the disturbance observer estimates the model uncertainty of the system. The estimated value is then fed to the composite SMC for disturbance compensation without using a high gain for switching control and thus reducing the effect of chattering in the input $[45,46]$. The weaknesses of this method is that initially it requires an unrealistic magnitude of control input to estimate the disturbance. Furthermore, the addition of disturbance observer in the system increases the order of the system and, thus, increases the computational complexity [44].

The HOSMC is an effective method to alleviate the chattering to a great extent without compromising with the precision of the controlled system performance [37,41,42]. In this method, the high frequency component of discontinuous control is applied into higher order derivative of sliding surface. Consequently, the chattering component in the actual input gets attenuated substantially. As a result, the high frequency input can not be propagated into the sliding surface or the original system [47-49]. Various forms of HOSMC approaches have been explored for the AMB system which are reported in [34,50-55], and references therein. In [50], an adaptive second-order SMC (SOSMC) is proposed that reports the uniformly ultimate boundness of sliding function and the system states are only guaranteed to be asymptotically stable. The SOSMC techniques are also realized for one DOF AMB system (e.g., thrust AMB and MAGLEV systems) [51-53], where there is no harmonic disturbance due to non-rotatory motion, and this leads to a simpler controller design. Further, a composite control scheme is presented in [34] by combining the PID and twisting SOSMC strategies. Although the developed controller guarantees the finitetime stability of closed-loop system; however, a priori assumption about the bounds of disturbance were considered before designing the controller that is not always feasible in practice. Another SOSMC strategy is proposed in [54] for the AMB system, where it is established that the sliding surface and its derivative are converging to zero in finite time, and the chattering problem near the origin is theoretically alleviated. However, in this paper, the dynamical model of the AMB system has not considered the system uncertainties and disturbances while designing the controller. In addition to this, gain parameters of the controller are not auto-tuned using some adaptive algorithm in order to avoid manual repeated attempts for their tuning. Recently, an integral adaptive second order SMC scheme is proposed in [55] where the finite time convergence is proved for both surface and state. However, noticeable chattering effect is still evident from the control response reported in that work.

From the above literature, it can be observed that the relaxation of a priori knowledge of disturbance bound, finite-time stability, and the alleviation of chattering using HOSMC has not been explored all together collectively. Therefore, this paper proposes an adaptive integral third-order SMC (AITOSMC), which in the authors' best knowledge, has not been studied for controller design of 5 DOF AMB systems. Therefore, the main features of this paper are as follows.

- This work investigates an adaptive integral third-order SMC for five DOF AMB system under unknown bounded model uncertainties and time-varying harmonic disturbances;

- $\quad$ The proposed control law is formulated by employing an auxiliary input, which is the first-order derivative of the actual control input. The auxiliary input contains the discontinuous input, i.e., the signum function components of SMC is in the firstorder derivative of the actual control input. As a result, the chattering problem is 
significantly reduced without compromising with the robustness, which is the case in the boundary layer technique;

- Unlike [34], the proposed approach implements two adaptive laws to relax the design assumption about a priori knowledge of upper bound of lumped disturbance;

- The system state trajectories are theoretically proved to be converging in finite-time under the proposed scheme;

- The comparative simulation analysis illustrates the superiority of the proposed controller over the second order SMC and the PID control in terms of faster response and a significant reduction in the chattering.

This paper is organized as follows. In Section 2, the five DOF AMB system description is presented. Problem formulation and controller design are described in Section 3. In Section 4, finite-time stability analysis of the sliding variable using the Lyapunov analysis is given, and the finite-time system state convergence is also proved by the homogeneity theory. Simulation results with the comparative study are presented in Section 5. The concluding remarks are discussed in Section 6.

\section{Modeling of the AMB System}

The schematic diagram of the AMB system with 5-DOF is shown in Figure 1. The system comprises of two radial AMBs (RAMB) at left and right, one thrust AMB (TAMB) and a motor at the middle. The task of RAMBs and TAMB is to stabilize the rotor movement by active five degree of freedom control. Therefore, two RAMBs take care of four radial DOF, whereas TAMB steers the axial DOF. Further, the rotor of the motor rotates at a constant speed.

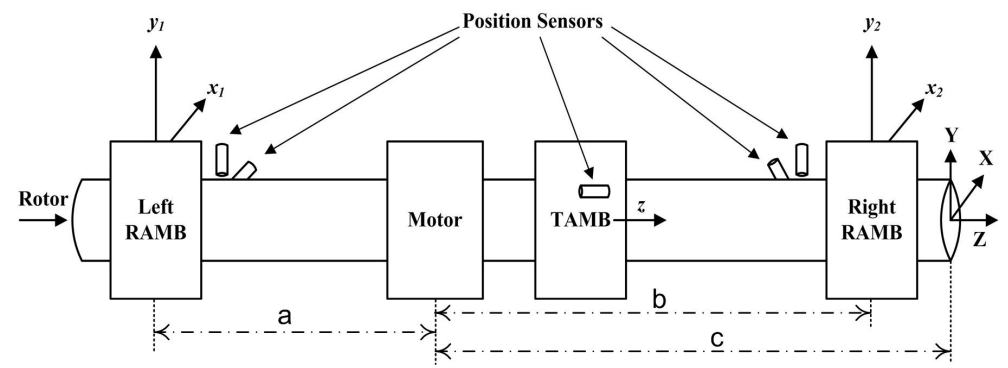

Figure 1. The layout of the rotor system by 5-DOF active magnetic suspension.

The individual RAMB is electrically constructed using four coils that are installed on the stators at its right, left, lower, and upper positions. These coils are energized using DC currents that generates attractive electromagnetic forces to neutralize the rotor deviation. The DC bias voltage $v_{b}$ is applied to generate the bias current $i_{b}$.

To represent the rotor displacement from the nominal position $x_{b}$, five coordinate variables, i.e., $x_{1}, y_{1}, x_{2}, y_{2}$, and $z$, are used. These coordinates are measured by five sensors which are mounted next to the AMBs, and the left and right RAMBs. The $X-Y$ position of the rotor for the left RAMB is denoted by $x_{1}, y_{1}$, likewise, $x_{2}, y_{2}$ coordinates represents the right RAMB, whereas the axial movement is denoted by $z$. Based on the sensor measurements, the control law regulates the rotor displacement to zero, i.e., $x_{1}=0$, $y_{1}=0, x_{2}=0, y_{2}=0$, and $z=0$ all in $\mathrm{mm}$. In other words, returns the shaft to its nominal air-gap position $\left(x_{b}, y_{b}, z_{b}\right)$. For example, if the rotor is displaced from the central position of the air-gap in the left direction of $X$-axis by $\bar{x}_{1}$ unit. Then, the air-gap remaining in left side will be $x_{b}-\bar{x}_{1}$ and on the right side it will be increased, i.e., $x_{b}+\bar{x}_{1}$. To overcome this rotor deviation, the RAMB will circulate the corresponding input currents through the left and right coils $i_{b}+i_{\bar{x}_{1}}$ and $i_{b}-i_{\bar{x}_{1}}$. Similarly, the rotor deviation in the $Z$ axis will be nullified by supplying the current inputs $\mathrm{i}_{b t}+\mathrm{i}_{\bar{z}}$ and $\mathrm{i}_{b t}-\mathrm{i}_{\bar{z}}$ through the TAMB coils.

The dynamics of AMB system is highly nonlinear because of the coupling of five axes along with the gyroscopic effects. The system also encounters attractive nonlinear 
forces, external disturbance forces, and system parameteric uncertainties. The expressions of nonlinear attractive forces acting on the axes of $X, Y$, and $Z$ are given as [56]

$$
\begin{aligned}
& \mathcal{F}_{x_{1}}=k\left(\frac{\left(\mathrm{i}_{b}+\mathrm{i}_{x_{1}}\right)^{2}}{\left(\mathrm{x}_{b}-x_{1}\right)^{2}}-\frac{\left(\mathrm{i}_{b}-\mathrm{i}_{x_{1}}\right)^{2}}{\left(\mathrm{x}_{b}+x_{1}\right)^{2}}\right) \\
& \mathcal{F}_{x_{2}}=k\left(\frac{\left(\mathrm{i}_{b}+\mathrm{i}_{x_{2}}\right)^{2}}{\left(\mathrm{x}_{b}-x_{2}\right)^{2}}-\frac{\left(\mathrm{i}_{b}-\mathrm{i}_{x_{2}}\right)^{2}}{\left(\mathrm{x}_{b}+x_{2}\right)^{2}}\right) \\
& \mathcal{F}_{y_{1}}=k\left(\frac{\left(\mathrm{i}_{b}+\mathrm{i}_{y_{1}}\right)^{2}}{\left(\mathrm{y}_{b}-y_{1}\right)^{2}}-\frac{\left(\mathrm{i}_{b}-\mathrm{i}_{y_{1}}\right)^{2}}{\left(\mathrm{y}_{b}+y_{1}\right)^{2}}\right) \\
& \mathcal{F}_{y_{2}}=k\left(\frac{\left(\mathrm{i}_{b}+\mathrm{i}_{y_{2}}\right)^{2}}{\left(\mathrm{y}_{b}-y_{2}\right)^{2}}-\frac{\left(\mathrm{i}_{b}-\mathrm{i}_{y_{2}}\right)^{2}}{\left(\mathrm{y}_{b}+y_{2}\right)^{2}}\right) \\
& \mathcal{F}_{z}=k\left(\frac{\left(\mathrm{i}_{b t}+\mathrm{i}_{z}\right)^{2}}{\left(\mathrm{z}_{b}-z\right)^{2}}-\frac{\left(\mathrm{i}_{b t}-\mathrm{i}_{z}\right)^{2}}{\left(\mathrm{z}_{b}+z\right)^{2}}\right)
\end{aligned}
$$

where the attractive forces $\mathcal{F}_{x_{1}}, \mathcal{F}_{x_{2}}, \mathcal{F}_{y_{1}}, \mathcal{F}_{y_{2}}, \mathcal{F}_{z}$ acts on the respective coils of $X, Y$, and $Z$ axes. The term $k$ denotes the parameter of electromagnet which is defined as $k=\frac{\mu_{0} A N^{2} \cos (\bar{\alpha})}{4}$, where $\mu_{0}$ is vacuum permeability, $A$ is pole area, $N$ is coil turns, and $\bar{\alpha}$ is angle between the magnetic poles [4]. One observation can be made from (2) that the attractive forces are directly proportional to the square of the currents and inversely related to the square of air-gaps.

The Taylor's expansions can be used to linearize the above nonlinear expression (2) at the nominal points. The nominal points of currents and air-gaps are all taken as zero. Therefore, the expressions of the electromagnetic forces in the linearized form are presented as [56]

$$
\begin{aligned}
\mathcal{F}_{x_{1}}\left(x_{1}, \mathrm{i}_{x_{1}}\right) & \cong k_{s i} i_{x_{1}}+k_{s p} x_{1} \\
\mathcal{F}_{x_{2}}\left(x_{2}, \mathrm{i}_{x_{2}}\right) & \cong k_{s i} i_{x_{2}}+k_{s p} x_{2} \\
\mathcal{F}_{y_{1}}\left(y_{1}, \mathrm{i}_{y_{1}}\right) & \cong k_{s i} i_{y_{1}}+k_{s p} y_{1} \\
\mathcal{F}_{y_{2}}\left(y_{2}, \mathrm{i}_{y_{2}}\right) & \cong k_{s i} i_{y_{2}}+k_{s p} y_{2} \\
\mathcal{F}_{z}\left(z, \mathrm{i}_{z}\right) & \cong k_{t i} \mathrm{i}_{z}+k_{t p} z
\end{aligned}
$$

where $k_{s p}$ and $k_{t p}$ are the position stiffness of the RAMBs and TAMB, respectively. Likewise, $k_{s i}$ and $k_{t i}$ are the current stiffness of the RAMBs and TAMB, respectively.

The rotor displacement positions are selected as the state variables which are expressed as $\mathbf{x}=\left[\begin{array}{llll}x_{1} & x_{2} & y_{1} & y_{2}\end{array}\right]^{T}$. The dynamics of the rotor displacement is coupled in nature. However, in $[29,57]$, the decoupled dynamics of five-axis rotor displacement position are

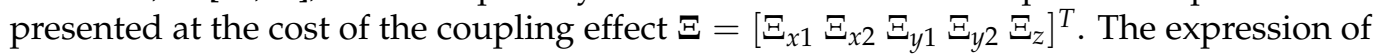
the decoupled dynamics are defined as

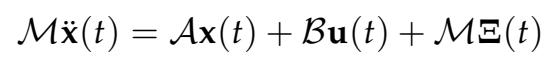

where $\mathbf{u}=\left[\begin{array}{lllll}i_{x_{1}} & i_{x_{2}} & i_{y_{1}} & i_{y_{2}} & i_{z}\end{array}\right]^{T}$ denotes the control input currents. The mass $\mathcal{M} \in \mathbf{R}^{5 \times 5}$, stiffness $\mathcal{A} \in \mathbf{R}^{5 \times 5}$, controller gain $\mathcal{B} \in \mathbf{R}^{5 \times 5}$, and $\boldsymbol{\Xi} \in \mathbf{R}^{5}$ are expressed as $[29,58]$ 


$$
\begin{aligned}
\mathcal{M} & =\left[\begin{array}{ccccc}
1 & 0 & 0 & 0 & 0 \\
0 & 1 & 0 & 0 & 0 \\
0 & 0 & 1 & 0 & 0 \\
0 & 0 & 0 & 1 & 0 \\
0 & 0 & 0 & 0 & 1
\end{array}\right], \\
\mathcal{A} & =\left[\begin{array}{ccccc}
k_{s p} \lambda_{1} & 0 & 0 & 0 & 0 \\
0 & k_{s p} \lambda_{3} & 0 & 0 & 0 \\
0 & 0 & k_{s p} \lambda_{1} & 0 & 0 \\
0 & 0 & 0 & k_{s p} \lambda_{3} & 0 \\
0 & 0 & 0 & 0 & k_{t p} \lambda_{4}
\end{array}\right], \\
\mathcal{B} & =\left[\begin{array}{ccccc}
k_{s i} \lambda_{1} & 0 & 0 & 0 & 0 \\
0 & k_{s i} \lambda_{3} & 0 & 0 & 0 \\
0 & 0 & k_{s i} \lambda_{1} & 0 & 0 \\
0 & 0 & 0 & k_{s i} \lambda_{3} & 0 \\
0 & 0 & 0 & 0 & k_{t i} \lambda_{4}
\end{array}\right],
\end{aligned}
$$

and $\Xi$ is defined as

$$
\Xi=\left[\begin{array}{c}
\Xi_{x 1} \\
\Xi_{x 2} \\
\Xi_{y 1} \\
\Xi_{y 2} \\
\Xi_{z}
\end{array}\right]=\left[\begin{array}{c}
-\delta_{1} \dot{y}_{1}+\delta_{1} \dot{y}_{2}+2 k_{s p} \lambda_{2} x_{2}+2 k_{s i} \lambda_{2} i_{x 2}+\mu_{1} f_{d t x} \\
\delta_{2} \dot{y}_{1}-\delta_{2} \dot{y}_{2}+2 k_{s p} \lambda_{2} x_{1}+2 k_{s i} \lambda_{2} i_{x 1}+\mu_{2} f_{d t x} \\
\delta_{1} \dot{x}_{1}-\delta_{1} \dot{x}_{2}+2 k_{s p} \lambda_{2} y_{2}+2 k_{s i} \lambda_{2} i_{y 2}+\mu_{1} f_{d t y}-g \\
-\delta_{2} \dot{x}_{1}-\delta_{2} \dot{x}_{2}+2 k_{s p} \lambda_{2} y_{1}+2 k_{s i} \lambda_{2} \dot{i}_{y 1}+\mu_{2} f_{d t y}-g \\
\mu_{3} f_{d t z}
\end{array}\right]
$$

where $\delta_{1}=\frac{\mathrm{a} J_{z} \omega}{J l}, \delta_{2}=\frac{\mathrm{b} J_{z} \omega}{J l}, \lambda_{1}=\left(\frac{1}{\mathrm{~m}}\right)+\left(\frac{\mathrm{a}^{2}}{J}\right), \lambda_{2}=\left(\frac{1}{\mathrm{~m}}\right)-\left(\frac{\mathrm{ab}}{J}\right), \lambda_{3}=\left(\frac{1}{\mathrm{~m}}\right)+\left(\frac{\mathrm{b}^{2}}{J}\right)$, $\lambda_{4}=\left(\frac{1}{\mathrm{~m}}\right), \mu_{1}=\left(\frac{1}{\mathrm{~m}}\right)-\left(\frac{\mathrm{ac}}{\mathrm{J}}\right), \mu_{2}=\left(\frac{1}{\mathrm{~m}}\right)+\left(\frac{\mathrm{bc}}{\mathrm{J}}\right), \mu_{3}=\left(\frac{1}{\mathrm{~m}}\right)$. Additionally, the parameters a, $b$, and $c$ are the lengths between the left RAMB and the center of gravity (CG), the right RAMB and CG, and the rotor end and CG, respectively. The mass and length of the rotor are scalar quantities and they are represented by $\mathrm{m}$ and I, respectively. Moreover, the rotor transverse mass moment of inertia about $\mathrm{X}$ and $\mathrm{Y}$ axes are considered to be the same and, thus, represented by a common term $J$. Whereas, the rotor polar mass moment of inertia is denoted by $J_{z}$. The external disturbance forces are represented by $f_{d t x}, f_{d t y}$, and $f_{d t z}$.

Since mass $\mathcal{M}$ is an identity matrix and matrices $\mathcal{A}$ and $\mathcal{B}$ are diagonal matrix, the individual dynamics of state $\mathbf{x}$ from (4) in the scalar form can be written as

$$
\ddot{x}_{j}(t)=a_{j} x_{j}(t)+b_{j} u_{j}(t)+\Xi_{j}(t) \text { for } j=1 \text { to } 5,
$$

where $a_{j}$ and $b_{j}$ are the $j^{\text {th }}$ diagonal element of $\mathcal{A}$ and $\mathcal{B}$, respectively. Now, these five decoupled individual dynamical equations can be written in a vector form as

$$
\ddot{\mathbf{x}}(t)=\mathcal{A} \mathbf{x}(t)+\mathcal{B} \mathbf{u}(t)+\Xi(t) .
$$

\section{Problem Statement}

The key objective of this work is to design a robust controller for the AMB system that will steer the central position of the rotor to the nominal air-gap location within a finite-time. In other words, the proposed controller must stabilize the states $\left(x_{1}, x_{2}, y_{1}, y_{2}\right.$, $z)$ to origin in finite-time while rejecting the uncertainties and disturbances. Mathematically it can be expressed as

$$
\lim _{t \rightarrow t_{f}} \mathbf{x}(t)=\mathbf{0}
$$

where $t_{f}$ is the finite-time. 


\section{The Proposed Control Strategy}

This section, first describes the formulation of problem and then the proposed control methodologies for AMB system is presented.

\subsection{Problem Formulation}

In a practical mechanical system, it is difficult to know the exact values of system parameters $\mathcal{A}$ and $\mathcal{B}$ due to the factors such as wear and tear, ageing, inaccurate modeling, etc. So, the system parameters can be represented as a nominal part and the uncertain part. Therefore, the decoupled system (10) can be expressed as [29]

$$
\ddot{\mathbf{x}}(t)=\left(\mathcal{A}_{n}+\Delta \mathcal{A}\right) \mathbf{x}(t)+\left(\mathcal{B}_{n}+\Delta \mathcal{B}\right) \mathbf{u}(t)+\boldsymbol{\Xi}(t)=\mathcal{A}_{n} \mathbf{x}(t)+\mathcal{B}_{n} \mathbf{u}(t)+\mathbf{d}(t),
$$

where $\mathcal{A}_{n} \in \mathbb{R}^{5 \times 5}$ and $\mathcal{B}_{n} \in \mathbb{R}^{5 \times 5}$ are the nominal components of $\mathcal{A}$ and $\mathcal{B}$. Whereas, $\Delta \mathcal{A} \in \mathbb{R}^{5 \times 5}, \Delta \mathcal{B} \in \mathbb{R}^{5 \times 5}$ are the time-varying alterations of the system parameters. The parameter $\mathbf{d} \in \mathbb{R}^{5 \times 5}$ is the lumped uncertainty, which is the combination of all the model uncertainties, coupling term $\mathbf{t}$, and disturbances, denoted as

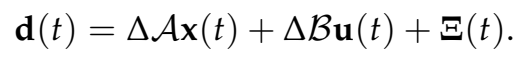

Some of the assumptions considered for the system (12) are as follows.

Assumption 1. The measurements of state variables and their first derivatives are accessible for the controller design.

Remark 1. The first time derivative of state variable $\mathbf{x}$ can be obtained using the Levant's finite-time differentiator [35], which evaluates the derivative of the input signal without actually performing the differentiation. The equation of Levant's differentiator is defined as

$$
\begin{aligned}
& \dot{\varphi}_{1}=-c_{1}\left|\varphi_{1}-\mathbf{x}\right|^{\frac{1}{2}} \operatorname{sgn}\left(\varphi_{1}-\mathbf{x}\right)+\varphi_{2}, \\
& \dot{\varphi}_{2}=-c_{2} \operatorname{sgn}\left(\varphi_{2}-\mathbf{x}\right),
\end{aligned}
$$

where $c_{1}>0, c_{2}>0$, and $c_{1}>c_{2}$. The variables $\varphi_{1} \in \mathbb{R}^{3}$ and $\varphi_{2} \in \mathbb{R}^{3}$ are, respectively, the real-time estimate of $\mathbf{x}$ and $\dot{\mathbf{x}}$.

Assumption 2. The lumped uncertainty $\mathbf{d}(t)$ is bounded and once continuously differentiable, such that $\|\mathbf{d}(t)\| \leq \underline{d}$ and $\|\dot{\mathbf{d}}(t)\| \leq \bar{d}$, where $\underline{d}$ and $\bar{d}$ are positive unknown constants.

Remark 2. The arguments in favour of smoothness and boundedness of $\mathbf{d}(t)$ are as follows: The designed auxiliary control law $\mathbf{v}(t)$ in (22) is itself the derivative of $\mathbf{u}(t)$. Therefore, $\mathbf{\mathbf { u }}(t)$ always exist and the input current to the AMB system is always bounded since it is derived from a rated output power circuit, which gives saturated output current. Furthermore, the terms in $\Xi(t)$ consist of inputs, measurable states, bounded coefficients, and gravitational and sinusoidal external disturbances. These are all bounded and at least once differentiable functions. The uncertain terms $\Delta \mathcal{A}$ and $\Delta \mathcal{B}$ are bounded because it comprises of physical system parameters, e.g., length, mass, moment of inertia, etc., $[29,59,60]$.

The system (12) can be redefined with a set of single ordinary differential equations by choosing the new state variables as

$$
\begin{aligned}
& \mathbf{x}_{1}=\mathbf{x} \in \mathbb{R}^{5} \\
& \mathbf{x}_{2}=\dot{\mathbf{x}} \in \mathbb{R}^{5} .
\end{aligned}
$$


Now, using (15) to redefine the system (12) as

$$
\begin{aligned}
& \dot{\mathbf{x}}_{1}=\mathbf{x}_{2}(t), \\
& \dot{\mathbf{x}}_{2}=\mathcal{A}_{n} \mathbf{x}_{1}(t)+\mathcal{B}_{n} \mathbf{u}(t)+\mathbf{d}(t) .
\end{aligned}
$$

\subsection{Proposed Control Design}

Since the proposed control methodology is based on the HOSMC, therefore, the first step is the selection of a sliding variable $\varsigma \in \mathbb{R}^{5}$, which is considered as

$$
\varsigma=\mathbf{x}_{1}
$$

The first, second, and third time derivative of $\varsigma$ yields

$$
\begin{aligned}
\dot{\boldsymbol{\zeta}} & =\dot{\mathbf{x}}_{1}=\mathbf{x}_{2}(t), \\
\ddot{\boldsymbol{\zeta}} & =\dot{\mathbf{x}}_{2}=\mathcal{A}_{n} \mathbf{x}_{1}(t)+\mathcal{B}_{n} \mathbf{u}(t)+\mathbf{d}(t), \\
\dddot{\boldsymbol{\zeta}} & =\ddot{\mathbf{x}}_{2}=\mathcal{A}_{n} \mathbf{x}_{2}(t)+\mathcal{B}_{n} \mathbf{v}(t)+\mathbf{p}(t),
\end{aligned}
$$

where $\mathbf{v}(t) \in \mathbb{R}^{5}=\dot{\mathbf{u}}(t)$ is the auxiliary control input, and $\mathbf{p}(t) \in \mathbb{R}^{5}=\dot{\mathbf{d}}(t)$.

Remark 3. The selected sliding variable (17) has a relative degree $r=2$ since the input term $\mathbf{u}(t)$ emerges on the second time derivative of $\boldsymbol{s}$.

The dynamics of the sliding variables can be represented as

$$
\begin{aligned}
& \dot{\boldsymbol{\sigma}}_{1}=\dot{\boldsymbol{\zeta}}=\sigma_{2}, \\
& \dot{\boldsymbol{\sigma}}_{2}=\ddot{\boldsymbol{\zeta}}=\mathcal{A}_{n} \mathbf{x}_{1}(t)+\mathcal{B}_{n} \mathbf{u}(t)+\mathbf{d}(t)=\sigma_{3}, \\
& \dot{\sigma}_{3}=\dddot{\boldsymbol{\zeta}}=\mathcal{A}_{n} \mathbf{x}_{2}(t)+\mathcal{B}_{n} \mathbf{v}(t)+\mathbf{p}(t),
\end{aligned}
$$

where $\sigma_{1} \in \mathbb{R}^{5}, \sigma_{2} \in \mathbb{R}^{5}$, and $\sigma_{3} \in \mathbb{R}^{5}$ are the local variables.

The obvious choice of the auxiliary input $\mathbf{v}(t)$ in the absence of lumped uncertainty (i.e., $\mathbf{p}(t)=0$ ) for the system (21) will be

$$
\mathbf{v}(t)=\mathcal{B}_{n}^{-1}\left\{-\mathcal{A}_{n} \mathbf{x}_{2}(t)+\boldsymbol{\phi}_{n}(t)\right\},
$$

where the function $\boldsymbol{\phi}_{n}(t) \in \mathbb{R}^{5}$ is the nominal part of $\mathbf{v}(t)$, which is designed in (25).

However, under lumped uncertainty, $\boldsymbol{\phi}_{n}(t)$ will not be sufficient to drive the state variables to origin. Therefore, the design of the proposed controller must ensure the global robustness against lumped disturbances meanwhile guaranteeing the finite-time stability of the closed-loop system. In view of the mentioned objectives, the proposed scheme combines the homogeneous control and the adaptive integral third-order SMC techniques.

The sliding part of the controller is developed using the proposed integral sliding surface $\mathbf{s} \in \mathbb{R}^{5}$, which is expressed as

$$
\mathbf{s}=\sigma_{3}(t)-\sigma_{3}\left(t_{0}\right)-\int_{t_{0}}^{t} \boldsymbol{\phi}_{n}(\tau) d \tau .
$$

where $\sigma_{3}\left(t_{0}\right)$ is the initial condition of $\sigma_{3}$. The derivative of $\mathbf{s}$ w.r.t. to time gives

$$
\dot{\mathbf{s}}=\dot{\sigma}_{3}(t)-\boldsymbol{\phi}_{n}(t) .
$$

The nominal input $\phi_{n} \in \mathbb{R}^{5}$ represents the homogeneity controller [61]. The proposed function of $\phi_{n}$ is defined as

$$
\boldsymbol{\phi}_{n}=-G_{1} \operatorname{sig}^{\gamma_{1}}\left(\sigma_{1}\right)-G_{2} \operatorname{sig}^{\gamma_{2}}\left(\sigma_{2}\right)-G_{3} \operatorname{sig}^{\gamma_{3}}\left(\sigma_{3}\right),
$$


where $G_{1}, G_{2}$, and $G_{3}$ are the surface coefficients that are chosen such that the polynomial $H^{3}+G_{3} H^{2}+G_{2} H+G_{1}$ becomes Hurwitz, and $\gamma_{i} \in(0,1)$ for $i=1,2,3$ satisfies $\gamma_{i-1}=$ $\frac{\gamma_{i} \gamma_{i+1}}{2 \gamma_{i+1}-\gamma_{i}}, i=2,3$ with $\gamma_{4}=1$. Moreover, the function $\operatorname{sig}^{\gamma_{i}}\left(\sigma_{i}\right) \in \mathbb{R}^{5}$ for $i=1,2,3$ is defined as

$$
\operatorname{sig}^{\gamma_{i}}\left(\sigma_{i}\right)=\left[\left|\sigma_{i 1}\right|^{\gamma_{i}} \operatorname{sign}\left(\sigma_{i 1}\right) \cdots\left|\sigma_{i 5}\right|^{\gamma_{i}} \operatorname{sign}\left(\sigma_{i 5}\right)\right]^{T}
$$

In the presence of lumped uncertainty $\mathbf{p}(t)$, the discontinuous control input $\boldsymbol{\phi}_{\text {dis }}$ will provide the robustness against $\mathbf{p}(t)$. Moreover, $\boldsymbol{\phi}_{\text {dis }}$ will also assure that the sliding variables will remain on the sliding surface. The discontinuous control is designed as

$$
\boldsymbol{\phi}_{\text {dis }}=-\hat{\alpha} \mathbf{s}-\hat{\beta} \operatorname{sign}(\mathbf{s})
$$

where $\hat{\alpha}$ and $\hat{\beta}$ are the estimate of $\alpha>0$ and $\beta \geq\|\mathbf{p}\|$, respectively. The adaptation laws of $\hat{\alpha}$ and $\hat{\beta}$ are defined as

$$
\begin{aligned}
& \dot{\hat{\alpha}}= \begin{cases}\frac{1}{\xi}\|\mathbf{s}\|^{2}, & \text { if }\|\mathbf{s}\|_{\infty} \geq \Lambda \\
\underline{\Lambda}, & \text { if }\|\mathbf{s}\|_{\infty}<\Lambda\end{cases} \\
& \dot{\hat{\beta}}= \begin{cases}\frac{1}{\varrho}\|\mathbf{s}\|_{1}, & \text { if }\|\mathbf{s}\|_{\infty} \geq \Lambda \\
\underline{\Lambda} & \text { if }\|\mathbf{s}\|_{\infty}<\Lambda\end{cases}
\end{aligned}
$$

where $\xi, \varrho$ are the adaption parameter, $\Lambda>0$ and $\underline{\Lambda} \geq 0$ are the design constants, $\|\mathbf{s}\|=\left(\sum_{i=1}^{5}\left|s_{i}\right|^{2}\right)^{\frac{1}{2}},\|\mathbf{s}\|_{\infty}=\max \left|s_{i}\right|,\|\mathbf{s}\|_{1}=\sum_{i=1}^{5}\left|s_{i}\right|$.

Now, the composite control input $\phi$ is expressed as

$$
\phi=\phi_{n}+\phi_{\text {dis }}
$$

Substituting the composite control input $\boldsymbol{\phi}$ in place of $\boldsymbol{\phi}_{n}$ in (22) to obtain the proposed overall auxiliary control input $\mathbf{v}(t)$, defined as

$$
\mathbf{v}(t)=\mathcal{B}_{n}^{-1}\left\{-\mathcal{A}_{n} \mathbf{x}_{2}+\boldsymbol{\phi}_{n}+\boldsymbol{\phi}_{\text {dis }}\right\}
$$

Remark 4. The proposed controller $\mathbf{v}(t)$ (31) has a discontinuity due to the discontinuous function $\hat{\beta} \operatorname{sign}(\mathbf{s})$. Moreover, the effect of discontinuous function is mostly reflected in the dynamics of $\dddot{\boldsymbol{s}}$ (21c). Thus, the chattering issue will be significantly reduced from the actual control input $\mathbf{u}(t)=\int \mathbf{v}(\mathfrak{t}) d \mathfrak{t}$ and, also, its effect will be least on the original system (16).

\section{Stability of the Closed-Loop System}

The stability analysis of the system (16) under the proposed control scheme is investigated in this section. The stability proof is demonstrated with the use of two theorems. Theorem 1 illustrates that the sliding phase will be achieved within finite-time. Whereas the next theorem guarantees that the state variables $\left(\mathbf{x}_{1}, \mathbf{x}_{2}\right)$ will also converge to origin within a finite-time.

The stability proofs are presented in view of the following two Lemmas.

Lemma 1. Ref. [62]: Consider a system (32) where $\mathcal{G}(\boldsymbol{w}) \in \mathbb{R}^{n}$ is continuous and $\boldsymbol{w}=\mathbf{0}$ is the equilibrium point.

$$
\dot{w}=\mathcal{G}(w)
$$

Suppose there exist a positive function $\mathcal{V}(w): \mathbb{R}^{n} \rightarrow \mathbb{R}$. Now, if the inequality (33) with a $>0$, $b \in(0,1)$, in an open neighborhood $U_{0} \subseteq \mathbb{R}^{n}$, is satisfied

$$
\dot{\mathcal{V}}(\boldsymbol{w}) \leq-a \mathcal{V}^{b}(\boldsymbol{w}), \quad w \in U_{0} \backslash\{0\}
$$

Then, the origin will be termed as a finite-time stable point. Furthermore, $\mathbf{0}$ will be called as a global finite-time stable point if $U_{0}=\mathbb{R}^{n}$. 
Lemma 2. Ref. [61]: Consider a homogeneous system (32) with $\boldsymbol{w}=\mathbf{0}$ being the asymptotically stable equilibrium point. Moreover, if the system (32) has a negative degree of homogeneity w.r.t. the dilation $(1,2, \cdots, n)$. Then, the equilibrium of this system is also globally finite-time stable.

Theorem 1. Under Assumption 2, consider the dynamical system (16). The action of the proposed control law (31) to the closed-loop system will guarantee the achievement of sliding phase in a finite-time. In other words, the sliding variable (23) will be forced to zero in finite-time.

Proof. Consider a Lyapunov function candidate $V_{1}$ as

$$
V_{1}=\frac{1}{2} \mathbf{s}^{T} \mathbf{s}+\frac{1}{2 \theta_{1}} \tilde{\alpha}^{2}+\frac{1}{2 \theta_{2}} \tilde{\beta}^{2},
$$

where $\tilde{\alpha}=\hat{\alpha}-\alpha$ and $\tilde{\beta}=\hat{\beta}-\beta$ represent the adaptive estimation errors, and $\theta_{1}>0$, $\theta_{2}>0$ are the adaptation gains, which are used to adjust the estimation rate of $\hat{\alpha}$ and $\hat{\beta}$, respectively.

Taking the time derivative of (34) yields

$$
\dot{V}_{1}=\mathbf{s}^{T} \dot{\mathbf{s}}+\frac{1}{\theta_{1}} \tilde{\alpha} \dot{\hat{\alpha}}+\frac{1}{\theta_{2}} \tilde{\beta} \dot{\hat{\beta}}
$$

Introducing the expressions of $\dot{\mathbf{s}}, \dot{\hat{\alpha}}$, and $\dot{\hat{\beta}}$ from (24), (28) and (29) into (35) gives

$$
\dot{V}_{1}=\mathbf{s}^{T}\left(\dot{\boldsymbol{\sigma}}_{3}-\boldsymbol{\phi}_{n}\right)+\frac{(\hat{\alpha}-\alpha)}{\xi \theta_{1}}\|\mathbf{s}\|^{2}+\frac{(\hat{\beta}-\beta)}{\varrho \theta_{2}}\|\mathbf{s}\|_{1} \text {. }
$$

Substituting the equation of $\dot{\sigma}_{3}$ from (21c) in (36) to obtain

$$
\dot{V}_{1}=\mathbf{s}^{T}\left(\mathcal{A}_{n} \mathbf{x}_{2}+\mathcal{B}_{n} \mathbf{v}+\mathbf{p}-\boldsymbol{\phi}_{n}\right)+\frac{(\hat{\alpha}-\alpha)}{\xi \theta_{1}}\|\mathbf{s}\|^{2}+\frac{(\hat{\beta}-\beta)}{\varrho \theta_{2}}\|\mathbf{s}\|_{1} .
$$

Putting the expression of proposed control law from (31) in (37) to get

$$
\begin{aligned}
\dot{V}_{1} & =\mathbf{s}^{T}\left(\boldsymbol{\phi}_{\text {dis }}+\mathbf{p}\right)+\frac{(\hat{\alpha}-\alpha)}{\xi \theta_{1}}\|\mathbf{s}\|^{2}+\frac{(\hat{\beta}-\beta)}{\varrho \theta_{2}}\|\mathbf{s}\|_{1}, \\
& =-\hat{\alpha} \mathbf{s}^{T} \mathbf{s}-\hat{\beta} \mathbf{s}^{T} \mathbf{s i g n}(\mathbf{s})+\mathbf{s}^{T} \mathbf{p}+\frac{(\hat{\alpha}-\alpha)}{\xi \theta_{1}}\|\mathbf{s}\|^{2}+\frac{(\hat{\beta}-\beta)}{\varrho \theta_{2}}\|\mathbf{s}\|_{1}, \\
& \leq-\hat{\alpha}\|\mathbf{s}\|^{2}-\hat{\beta}\|\mathbf{s}\|_{1}+\|\mathbf{s}\|\|\mathbf{p}\|+\frac{(\hat{\alpha}-\alpha)}{\xi \theta_{1}}\|\mathbf{s}\|^{2}+\frac{(\hat{\beta}-\beta)}{\varrho \theta_{2}}\|\mathbf{s}\|_{1}, \\
& \leq-\hat{\alpha}\|\mathbf{s}\|^{2}-\hat{\beta}\|\mathbf{s}\|_{1}+\bar{d}\|\mathbf{s}\|+\frac{(\hat{\alpha}-\alpha)}{\xi \theta_{1}}\|\mathbf{s}\|^{2}+\frac{(\hat{\beta}-\beta)}{\varrho \theta_{2}}\|\mathbf{s}\|_{1} .
\end{aligned}
$$

Since $\alpha>0$, a term $\alpha\|\mathbf{s}\|^{2}>0$ can be introduced in the above inequality (38). Further, a term $\beta\|\mathbf{s}\|_{1}$ is added and subtracted in (38). Therefore,

$$
\begin{aligned}
\dot{V}_{1} & \leq \frac{\hat{\alpha}-\alpha}{\xi \theta_{1}}\|\mathbf{s}\|^{2}+\frac{\hat{\beta}-\beta}{\varrho \theta_{2}}\|\mathbf{s}\|_{1}+\alpha\|\mathbf{s}\|^{2}+\beta\|\mathbf{s}\|_{1}-\beta\|\mathbf{s}\|_{1}-\hat{\alpha}\|\mathbf{s}\|^{2}-\hat{\beta}\|\mathbf{s}\|_{1}+\bar{d}\|\mathbf{s}\|, \\
& =\frac{\hat{\alpha}-\alpha}{\xi \theta_{1}}\|\mathbf{s}\|^{2}+\frac{\hat{\beta}-\beta}{\varrho \theta_{2}}\|\mathbf{s}\|_{1}-(\hat{\alpha}-\alpha)\|\mathbf{s}\|^{2}-(\hat{\beta}-\beta)\|\mathbf{s}\|_{1}-(\beta-\bar{d})\|\mathbf{s}\|, \\
& =-(\beta-\bar{d})\|\mathbf{s}\|+\tilde{\alpha} \frac{1}{\xi \theta_{1}}\|\mathbf{s}\|^{2}+\tilde{\beta} \frac{1}{\varrho \theta_{2}}\|\mathbf{s}\|_{1}-\tilde{\alpha}\|\mathbf{s}\|^{2}-\tilde{\beta}\left\|_{\mathbf{s}}\right\|_{1}
\end{aligned}
$$


Further simplifying (39) by following the similar steps taken in [63] as

$$
\begin{aligned}
\dot{V}_{1} & \leq-(\beta-\bar{d})\|\mathbf{s}\|-\tilde{\alpha}\left(\|\mathbf{s}\|^{2}-\frac{\|\mathbf{s}\|^{2}}{\xi \theta_{1}}\right)-\tilde{\beta}\left(\|\mathbf{s}\|_{1}-\frac{\|\mathbf{s}\|_{1}}{\varrho \theta_{2}}\right) \\
& \leq-\sqrt{2} \vartheta_{1} \frac{\|\mathbf{s}\|}{\sqrt{2}}-\sqrt{2 \theta_{1}} \vartheta_{2} \frac{\tilde{\alpha}}{\sqrt{2 \theta_{1}}}-\sqrt{2 \theta_{2}} \vartheta_{3} \frac{\tilde{\beta}}{\sqrt{2 \theta_{2}}},
\end{aligned}
$$

where $\vartheta_{1}=(\beta-\bar{d})>0, \vartheta_{2}=\left(\|\mathbf{s}\|^{2}-\frac{\|\mathbf{s}\|^{2}}{\xi \theta_{1}}\right)>0$, and $\vartheta_{3}=\left(\|\mathbf{s}\|_{1}-\frac{\|\mathbf{s}\|_{1}}{\varrho \theta_{2}}\right)>0$. Therefore, (40) can be written as [64]

$$
\begin{aligned}
\dot{V}_{1} & \leq-\sqrt{2} \min \left(\vartheta_{1}, \sqrt{\theta_{1}} \vartheta_{2}, \sqrt{\theta_{2}} \vartheta_{3}\right)\left(\frac{\|\mathbf{s}\|}{\sqrt{2}}+\frac{\tilde{\alpha}}{\sqrt{2 \theta_{1}}}+\frac{\tilde{\beta}}{\sqrt{2 \theta_{2}}}\right) \\
& \leq-\vartheta\left(\frac{\|\mathbf{s}\|^{2}}{2}+\frac{\tilde{\alpha}^{2}}{2 \theta_{1}}+\frac{\tilde{\beta}^{2}}{2 \theta_{2}}\right)^{\frac{1}{2}} \\
\dot{V}_{1} & \leq-\vartheta V_{1}^{\frac{1}{2}},
\end{aligned}
$$

where $\vartheta=\min \left(\sqrt{2} \vartheta_{1}, \sqrt{2 \theta_{1}} \vartheta_{2}, \sqrt{2 \theta_{2}} \vartheta_{3}\right)>0$ for $\xi>1 / \theta_{1}$ and $\varrho>1 / \theta_{2}$. Therefore, Equation (41) is in line with the inequality given in Lemma 1. Thus, the proposed controller guarantees that the sliding variable is converging to zero in the finite-time.

Remark 5. Once s converges to zero, the sliding dynamics (21) will maintain the sliding phase under the action of switching control $\boldsymbol{\phi}_{\text {dis }}$. Moreover, the lumped disturbances will not affect the dynamics (21) during the sliding phase and, thus, the system will abide the nominal dynamics, i.e., $\dot{\sigma}_{3}=\phi_{n}$

Theorem 2. Under the sliding phase $(s=0)$, consider the sliding variable dynamics (21). The proposed control scheme (31) will regulate the state variables to origin with global finite-time results.

Proof. From Remark 5, the dynamics of the closed-loop system, once the sliding mode is achieved (i.e., $\mathbf{s}=0$ ), can be written as

$$
\begin{aligned}
& \dot{\sigma}_{1}=\sigma_{2} \\
& \dot{\sigma}_{2}=\sigma_{3} \\
& \dot{\sigma}_{3}=\phi_{n}=-G_{1} \operatorname{sig}^{\gamma_{1}}\left(\sigma_{1}\right)-G_{2} \operatorname{sig}^{\gamma_{2}}\left(\sigma_{2}\right)-G_{3} \operatorname{sig}^{\gamma_{3}}\left(\sigma_{3}\right)
\end{aligned}
$$

The closed-loop system has now become a triple integrator system with the feedback control $\boldsymbol{\phi}_{n}$. The proof of global finite-time stability of the system (42) is similar to the proof given in Proposition 8.1 of [65] using homogeneity theory. Therefore, for brevity, it is omitted from this paper.

\section{Simulation Analysis with Comparative Study}

In this section, the performance of the proposed adaptive integral third-order sliding mode controller (AITOSMC) for the five DOF AMB system is validated using numerical simulations. Furthermore, to demonstrate the comparative analysis, two different control schemes are also implemented for the same system, i.e., adaptive integral second-order sliding mode controller (AISOSMC), and a proportional integral derivative (PID) controller.

The parameters for AMB system are listed in Table 1 [29,59]. The bias DC currents are given in the coils of RAMBs and TAMB $\left(i_{b}=0.9\right.$ A and $\left.i_{b t}=1.1 \mathrm{~A}\right)$ to keep the position of suspended rotor in the middle of air-gap and neutralize its weight. The nominal air gap of RAMBs $\left(\mathrm{x}_{b}, \mathrm{y}_{b}\right)$ is chosen as $0.4 \mathrm{~mm}$, and for the TAMB $\left(\mathrm{z}_{b}\right)$ it is selected as $0.5 \mathrm{~mm}$. The 
rated rotational speed of the shaft is considered as $2400 \mathrm{rpm}$. The exogenous disturbance force exerted on the system along with the white noise $\eta \in \mathbb{R}^{3}$ is considered as $[6,58]$

$$
\left[\begin{array}{l}
f_{d t x} \\
f_{d t y} \\
f_{d t z}
\end{array}\right]=\left[\begin{array}{c}
0.1 \sin (t) \\
0.2 \sin (5 t) \\
0.3 \sin (8 t)
\end{array}\right]+5 \times 10^{-2} \eta
$$

Table 1. Physical parameters of five DOF AMB system [29,59].

\begin{tabular}{cc} 
Parameters & Value \\
\hline Rotor $(\mathrm{R})$ Mass $(\mathrm{m})$ & $2.56478 \mathrm{~kg}$ \\
R Length $(\mathrm{L})$ & $0.505 \mathrm{~m}$ \\
R Diameter $(d)$ & $0.0166 \mathrm{~m}$ \\
R transverse mass moment of inertia about X and Y axis $(J)$ & $0.04004 \mathrm{~kg} \cdot \mathrm{m}^{2}$ \\
R polar mass moment of inertia about Z axis $\left(J_{z}\right)$ & $0.0006565 \mathrm{~kg} \cdot \mathrm{m}^{2}$ \\
Length between center of gravity and left RAMB $(\mathrm{a})$ & $0.16 \mathrm{~m}$ \\
Length between center of gravity and right RAMB $(\mathrm{b})$ & $0.19 \mathrm{~m}$ \\
Distance between left RAMB and right RAMB $(\mathrm{I})$ & $0.35 \mathrm{~m}$ \\
Distance between center of gravity and end of rotor $(\mathrm{c})$ & $0.263 \mathrm{~m}$ \\
Current stiffness for thrust AMB $\left(k_{t i}\right)$ & $40 \mathrm{~N} / \mathrm{A}$ \\
Position stiffness for thrust AMB $\left(k_{t p}\right)$ & $36,000 \mathrm{~N} / \mathrm{m}$ \\
Current stiffness for radial AMB $\left(k_{s i}\right)$ & $80 \mathrm{~N} / \mathrm{A}$ \\
Position stiffness for thrust AMB $\left(k_{s p}\right)$ & $220,000 \mathrm{~N} / \mathrm{m}$ \\
\hline
\end{tabular}

Whereas, the system parameter uncertainties, i.e., $\Delta \mathcal{A}$ and $\Delta \mathcal{B}$ are taken as $15 \%$ and $20 \%$, of the respective nominal matrices. Furthermore, in order to test the effectiveness of the proposed strategy, the random Gaussian white noise vector with the magnitude of $2 \times 10^{-4} \mathrm{~mm}$ is also considered in the state feedback measurements.

Throughout the simulations, the initial conditions are selected as

$$
\left[x_{1}(0), x_{2}(0), y_{1}(0), y_{2}(0), z(0)\right]=[-0.2,0.1,0.2,0.15,-0.4] \mathrm{mm} \text {. }
$$

In the subsequent subsections, first, the simulation results of all the three control techniques are presented separately, then the comparison analysis is drawn based on the overall closed-loop performances.

\subsection{The Proposed AITOSMC Strategy}

The parameters of the proposed controller (31) are shown in Table 2.

Table 2. Control parameters of AITOSMC.

\begin{tabular}{ccccc}
\hline$G_{1}=355$ & $\gamma_{1}=0.4374$ & $\xi=1000$ & $\hat{\alpha}(0)=2000$ & $c_{1}=5.5$ \\
\hline$G_{2}=440$ & $\gamma_{2}=0.5384$ & $\varrho=100$ & $\hat{\beta}(0)=0$ & $c_{2}=0.25$ \\
\hline$G_{3}=250$ & $\gamma_{3}=0.7$ & $\Lambda=1 \times 10^{-2}$ & $\underline{\Lambda}=3 \times 10^{-5}$ & - \\
\hline
\end{tabular}

The time response of the rotor positions on the application of AITOSMC is presented in Figure 2. From this figure, it can be observed that the rotor displacements are regulated to the neighborhood of origin. This implies that the rotor returns back to the nominal position of the air-gap. The settling time of the system state is measured at the time when $|\mathbf{x}(t)|_{\infty} \leq 1 \times 10^{-6} \mathrm{~m}$ and stays within this bound. In the proposed approach, the settling time is found to be $0.863 \mathrm{~s}$. The steady-state response of the rotor displacement trajectory is also included in the zoomed-in response in Figure 2. The steady-state convergence bound has the magnitude of the order $10^{-8} \mathrm{~m}$. 


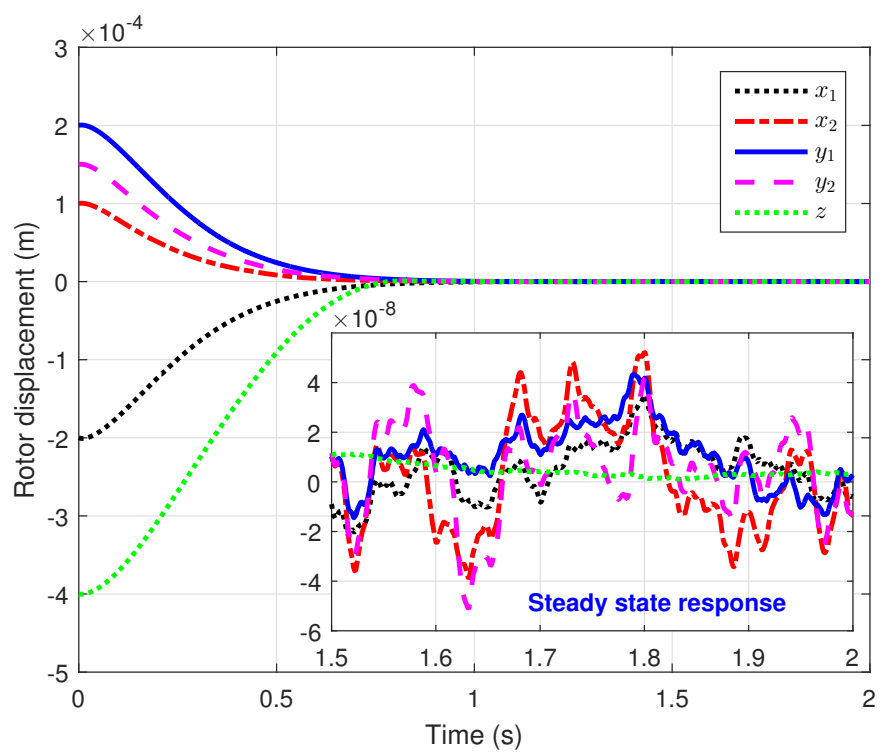

Figure 2. The responses of rotor positions under AITOSMC.

The time-varying control inputs response of the AITOSMC is presented in Figure 3. All the components of the control input reaches to the steady-state in $0.8 \mathrm{~s}$. However, the three components of the control input, i.e., $i_{x_{1}}, i_{x_{2}}, i_{z}$ settles down to the vicinity of origin, and $i_{y_{1}}, i_{y_{2}}$ approaches to the steady-state value of $0.18 \mathrm{~A}$, as shown in Figure 3 . Although the rotor positions settles down to the nominal values in $0.8 \mathrm{~s}$, the proposed input currents are applying the electro-magnetic force for negating the effects of uncertainties and disturbances present in the system for the whole simulation time. Moreover, it can be seen from the zoomed-in response of steady-state in Figure 3 that the chattering is significantly reduced under the proposed scheme. The chattering converges to the bound of approximately $3 \times 10^{-3} \mathrm{~A}$.

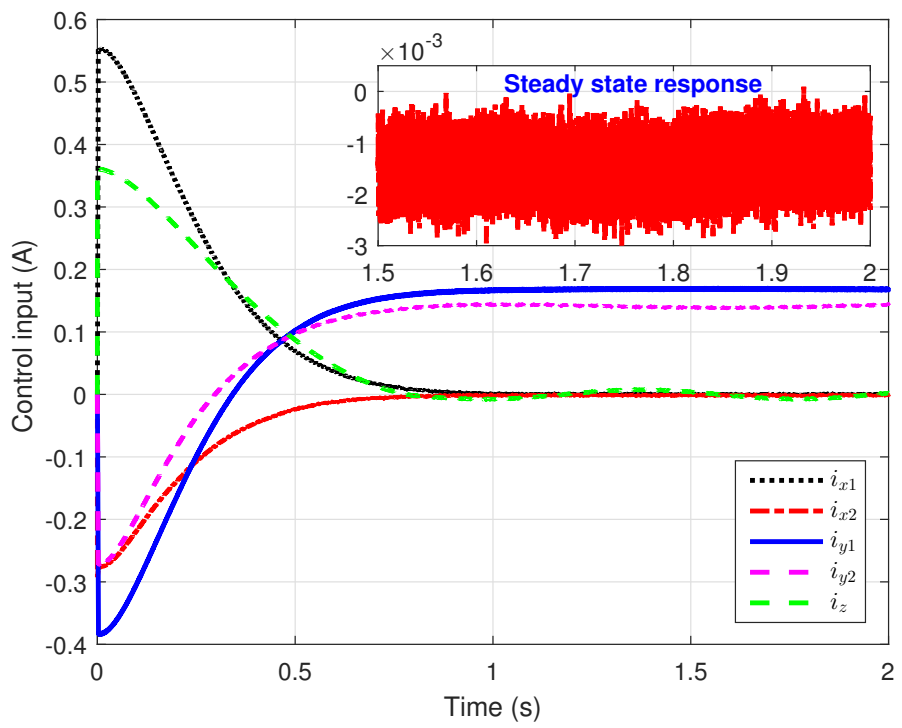

Figure 3. Time response of control inputs using AITOSMC.

The adaptive gains for the proposed controller are plotted in Figure 4. The adaptive estimation gain $\hat{\alpha}$ settles to the value of 2300.6 within $0.8 \mathrm{~s}$ and the other adaptive parameter $\hat{\beta}$ reaches to the estimate of $3.2 \times 10^{-3}$ within $0.8 \mathrm{~s}$. 


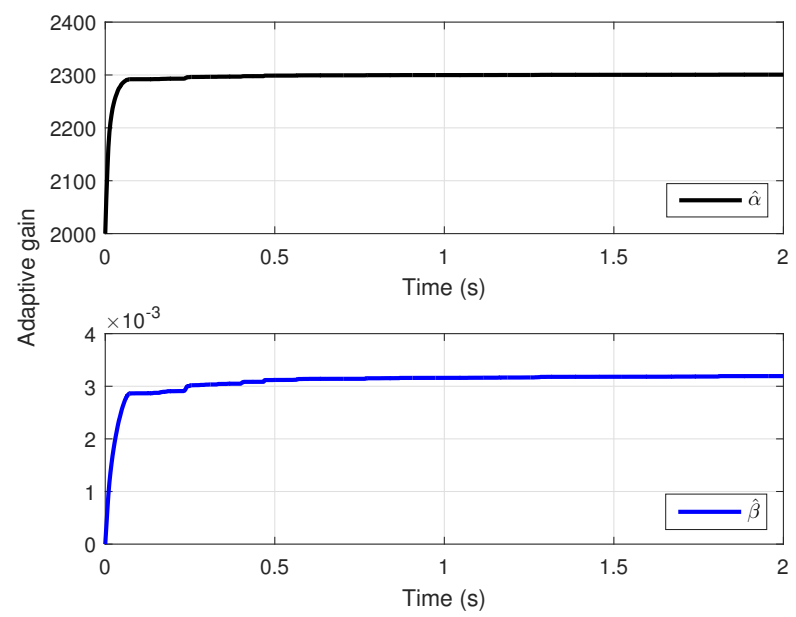

Figure 4. Adaptive gains of ITOSMC.

\subsection{The AISOSMC Strategy}

The strategy of the AISOSMC was proposed in [55]. The parameters of the AISOSMC, which are selected for the AMB system, is tabulated in Table 3.

Table 3. Control parameters of AISOSMC.

\begin{tabular}{cccc}
\hline$G_{1}=200$ & $\gamma_{1}=0.5$ & $\xi=0.001$ & $\hat{\alpha}(0)=500$ \\
\hline$G_{2}=350$ & $\Lambda=1 \times 10^{-2}$ & $\varrho=100$ & $\hat{\beta}(0)=0$ \\
\hline
\end{tabular}

The performance of rotor deviations under AISOSMC is shown in Figure 5. The rotor displacements are regulated to the neighborhood of zero from the initial deviations in 0.994 $\mathrm{s}$ and stays within the bound of $|\mathbf{x}(t)|_{\infty} \leq 1 \times 10^{-6} \mathrm{~m}$. The zoomed-in plot in Figure 5 shows the residual bound of displacement which is in the range of $10^{-8} \mathrm{~m}$.

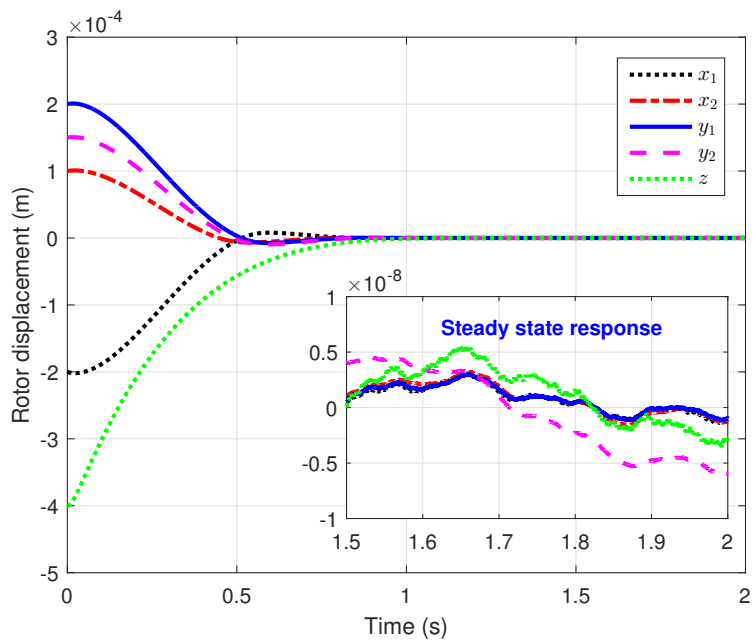

Figure 5. The responses of rotor positions under AISOSMC.

In Figure 6, the time-varying control inputs are plotted using AISOSMC. Similar to the response of AITOSMC, here also $i_{x 1}, i_{x 2}, i_{z}$ goes to the bound of zero at around $1 \mathrm{~s}$, and the other two components remain at a non-zero position in order to tackle the uncertainty and external disturbances. The control response has a chattering of the order $4 \times 10^{-2} \mathrm{~A}$, (see zoomed-in plot of Figure 6). 


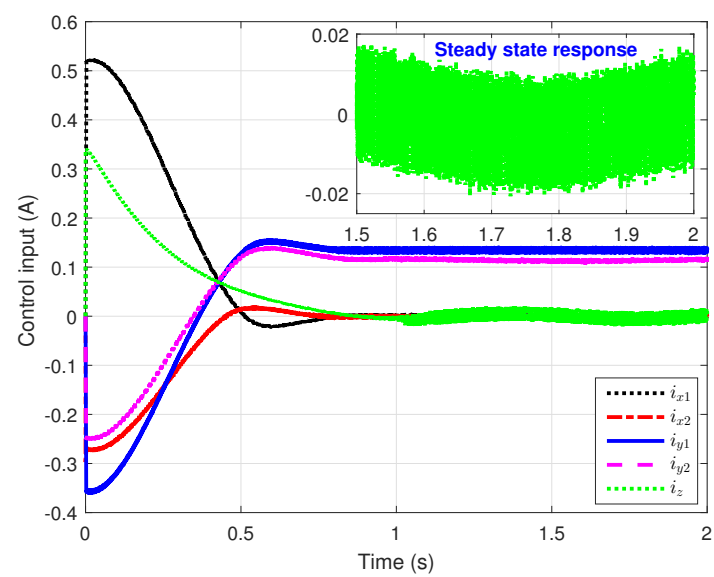

Figure 6. Time response of control inputs using AISOSMC.

The adaptive gains of ISOSMC are given in Figure 7. It is evident that the adaptive gains $\hat{\alpha}$ and $\hat{\beta}$ are converging to the values of 573.8 and $5.0 \times 10^{-3}$, respectively, in $0.8 \mathrm{~s}$.

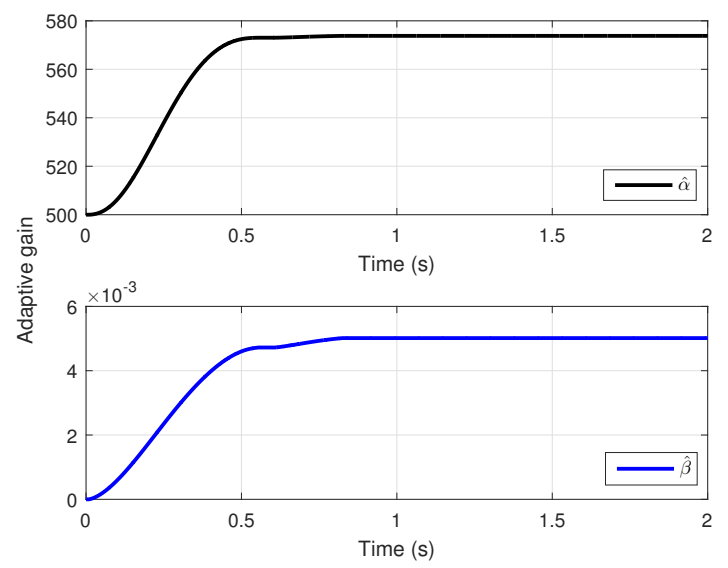

Figure 7. Adaptive gains of ISOSMC.

\subsection{The PID Control Approach}

In the PID control approach, the gains of the PID controller are chosen as $K_{p}=4000$, $K_{i}=5000$, and $K_{d}=20$. The time response for rotor displacements is plotted using the PID controller in Figure 8. It can be seen from the figure that the rotor deviations reach the neighborhood of zero in $1.25 \mathrm{~s}$. At a steady-state, all the state variables remain in the neighborhood of zero and have a steady-state bound of the order $5 \times 10^{-6} \mathrm{~m}$.

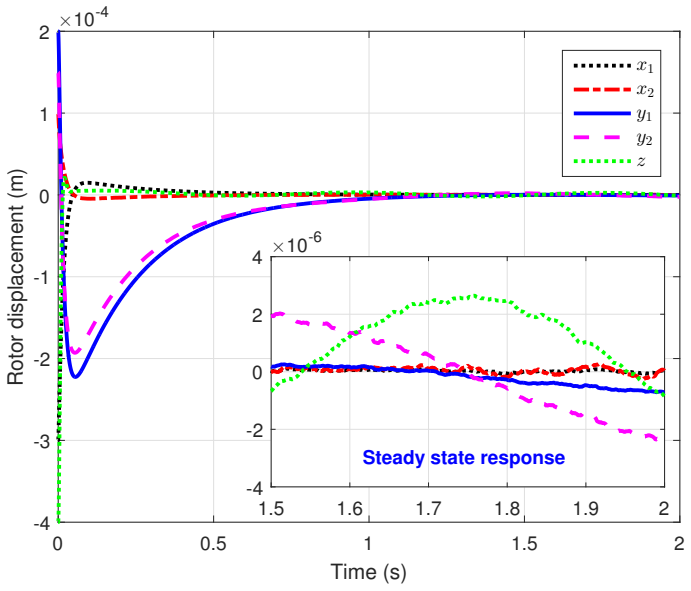

Figure 8. The responses of rotor positions under PID control. 
Figure 9 depicts the time response of the control input. In comparison to the previous two approaches, the initial current requirement is high and it is of the magnitude of $1.6 \mathrm{~A}$. During the steady-state, the magnitude of current ranges within the bound of $2 \times 10^{-2} \mathrm{~A}$ for $i_{x 1}, i_{x 2}, i_{z}$. The presence of chattering effect in the zoomed-in plot of Figure 9 is because of the consideration of white noise in the input channel.

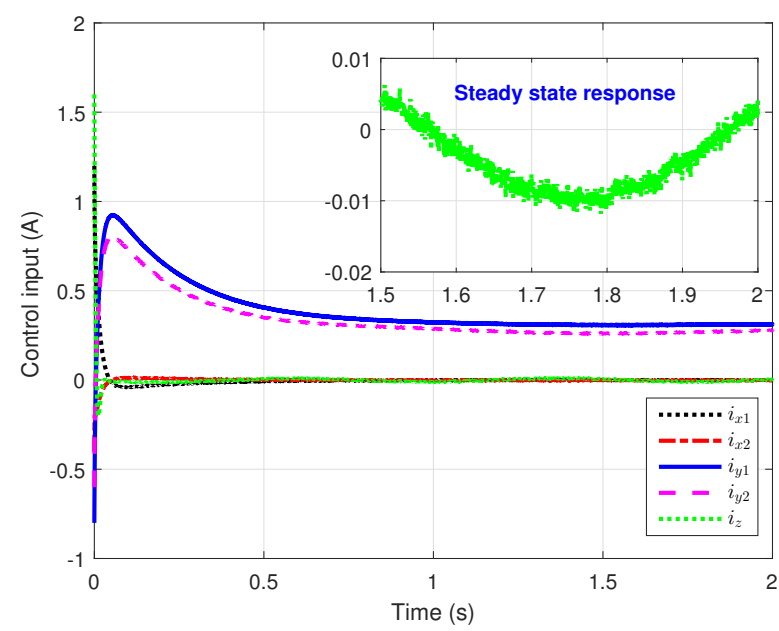

Figure 9. Time response of control inputs using PID.

\subsection{Comparison between the Three Control Techniques}

The overall comparison between the three control techniques are summarized in Table 4. It is evident from the Table 4 that the convergence of the system state trajectories to the settling condition is faster under the proposed AITOSMC than the AISOSMC and PID controllers. However, between the AITOSMC and AISOSMC, the steady-state convergence bound of AISOSMC is slightly better than AITOSMC, as shown in Table 4. The reason for the same is, AISOSMC is directly canceling the lumped disturbance $\mathbf{d}(t)$ using the discontinuous control. On the other hand, AITOSMC is rejecting the derivative of the disturbance $\mathbf{p}(t)$ using discontinuous auxiliary control input $\mathbf{v}(t)$. Thus, the strength of discontinuous switching function in the proposed controller $\mathbf{u}(t)$ is slightly lesser than AISOSMC scheme. Nevertheless, the cost product of norm of steady-state and order of chattering is still better in the proposed scheme, i.e., $0.612 \times 10^{-12}$ in AITOSMC and $2.72 \times 10^{-12}$ in AISOSMC.

Table 4. Comparative performance measures of three control schemes.

\begin{tabular}{ccccc}
\hline $\begin{array}{c}\text { Control } \\
\text { Schemes }\end{array}$ & $\begin{array}{c}\text { Settling } \\
\text { Time }(\mathbf{s})\end{array}$ & $\begin{array}{c}\left\|\mathbf{x}_{\mathbf{1}}\right\| \text { at } \\
\text { Steady State }\end{array}$ & $\begin{array}{c}\text { Order of } \\
\text { Chattering }\end{array}$ & $\begin{array}{c}\text { Total } \\
\text { Variations }\end{array}$ \\
\hline AITOSMC & 0.863 & $2.04 \times 10^{-8}$ & $3 \times 10^{-3}$ & 597.7 \\
AISOSMC & 0.994 & $6.80 \times 10^{-9}$ & $4 \times 10^{-2}$ & 3714.5 \\
PID & 1.251 & $2.58 \times 10^{-6}$ & - & - \\
\hline
\end{tabular}

Although the time response of the PID control input is free from high frequency chattering, the transient and steady-state performance is not as good as the other two SMC strategies. Furthermore, a larger magnitude of the control effort is employed during its transient response. In the input response of AISOSMC, there is noteworthy chattering, while the proposed AITOSMC approach significantly alleviates the chattering, as shown in Table 4. To quantify the amount of chattering in these two SMC schemes, the total variation (TV) parameters are calculated. The TV can be defined as the sum of absolute change 
between the present and the immediate past input values over time. The TV parameter is measured using the following expression

$$
T V=\sum_{i=1}^{5} \sum_{k=1}^{n}\left|u_{i}(k+1)-u_{i}(k)\right|
$$

where $n$ is the total number of iteration samples and $i$ is the control components. The response of absolute variations of input over time is plotted in Figure 10. The calculated values of TV for both AISOSMC and AITOSMC schemes is also presented in Table 4. It is evident from the Table 4 and Figure 10 that the change in the control input is less in the proposed scheme than the AISOSMC. This implies, in theory as well, the input chattering is substantially reduced under the AITOSMC approach.

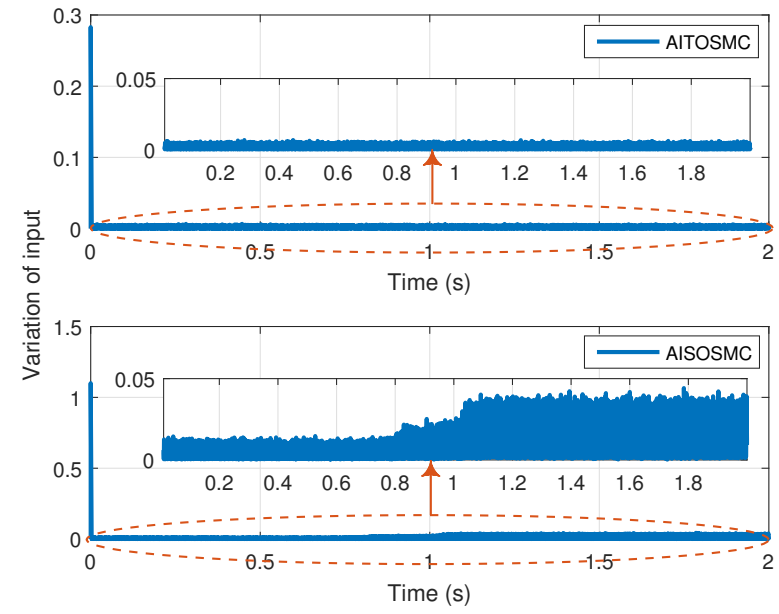

Figure 10. Time history of total variations for the AISOSMC and the proposed AITOSMC.

\section{Conclusions}

This paper has proposed an AITOSMC for the regulation of displaced five DOF AMB system under model uncertainties unknown time-varying disturbances and measurement noises. The bound of the lumped uncertainty was not assumed in advance, and the proposed control design has employed the adaptive laws to estimate the gains. With the use of AITOSMC, the problem of chattering has also been significantly alleviated. The stability analysis of the closed-loop system guarantees the finite-time convergence of the sliding variable and the state trajectories of the AMB system to the origin. The proposed methodology has been validated and compared with state-of-the-art using numerical simulations. The simulation results illustrates the effective performance of the closed-loop system and demonstrate a significant reduction in the chattering, faster rate of convergence for the system states, and better cost product of steady-state and order of chattering. The potential future extension of this work could be made along the lines of incorporating the rotor flexibilities and gyroscopic effects in the AMB system while designing the robust controller.

Author Contributions: Conceptualization, S.S. and S.M.A.; methodology, S.M.A.; software, S.S.; validation, S.S. and S.M.A.; formal analysis, S.S., S.M.A., and A.B.; investigation, S.S. and S.M.A.; resources, M.N. and A.S.S.; data curation, S.S.; writing-original draft preparation, S.S. and S.M.A.; writing-review and editing, S.S., S.M.A., A.B., and A.S.S.; visualization, S.S. and S.M.A.; supervision, M.N.; funding acquisition, A.S.S. All authors have read and agreed to the published version of the manuscript.

Funding: The APC was funded by Research Groups Program, grant number (RGP.1/299/42), King Khalid University, Saudi Arabia. 
Acknowledgments: The authors extend their appreciation to the Deanship of Scientific Research at King Khalid University for funding this work through Research Groups Program under grant number (RGP.1/299/42).

Conflicts of Interest: The authors declare no conflicts of interest.

\section{References}

1. Bleuler, H.; Cole, M.; Keogh, P.; Larsonneur, R.; Maslen, E.; Okada, Y.; Schweitzer, G.; Traxler, A. Magnetic Bearings: Theory, Design, and Application to Rotating Machinery; Springer Science \& Business Media: Berlin/Heidelberg, Germany, 2009.

2. Saha, S.; Nabi, M. A review on active magnetic bearing and exploitation of parametric model order reduction. In Proceedings of the 2016 11th International Conference on Industrial and Information Systems (ICIIS), Roorkee, India, 3-4 December 2016; pp. 420-425.

3. Saha, S.; Amrr, S.M.; Nabi, M.; Iqbal, A. Reduced Order Modeling and Sliding Mode Control of Active Magnetic Bearing. IEEE Access 2019, 7, 113324-113334. [CrossRef]

4. Hutterer, M.; Schrödl, M. Control of active magnetic bearings in turbomolecular pumps for rotors with low resonance frequencies of the blade wheel. Lubricants 2017, 5, 26. [CrossRef]

5. Han, B.; Liu, X.; Zheng, S. A novel integral 5-DOFs hybrid magnetic bearing with one permanent magnet ring used for turboexpander. Math. Probl. Eng. 2014, 2014, 18. [CrossRef]

6. Chen, L.; Zhu, C.; Wang, M.; Jiang, K. Vibration control for active magnetic bearing high-speed flywheel rotor system with modal separation and velocity estimation strategy. J. Vibroeng. 2015, 17, 757-775.

7. Wan, L.; Yang, Z.; Sun, X.; Chen, Z.; Chen, L. Decoupling control of a 5-degree-of-freedom bearingless induction motor based on least squares support vector machine inverse. Adv. Mech. Eng. 2016, 8. [CrossRef]

8. Knospe, C.R. Active magnetic bearings for machining applications. Control Eng. Pract. 2007, 15, 307-313. [CrossRef]

9. Wampler, R.K.; Lancisi, D.M. Active Magnetic Bearing System for Blood Pump. U.S. Patent 6,264,635, 3 December 1998.

10. Burdet, L. Active Magnetic Bearing Design and Characterization for High Temperature Applications; Technical Report for EPFL; Epfl: Lausanne, Switzerland, 2006.

11. Rajagopal, K.; Sivadasan, K. Low-stiction magnetic bearing for satellite application. J. Appl. Phys. 2002, 91, 6994-6996. [CrossRef]

12. Pichot, M.; Kajs, J.; Murphy, B.; Ouroua, A.; Rech, B.; Hayes, R.; Beno, J.H.; Buckner, G.; Palazzolo, A. Active magnetic bearings for energy storage systems for combat vehicles. IEEE Trans. Magn. 2001, 37, 318-323. [CrossRef]

13. Moon, F.C. Superconducting Levitation: Applications to Bearings and Magnetic Transportation; John Wiley \& Sons: Weinheim, Germany, 2008.

14. Turk, N.; Bulić, N.; Gruber, W. Nonlinear control of a bearingless flux-switching slice motor with combined winding system. IEEE/ASME Trans. Mechatron. 2019, 25, 152-163. [CrossRef]

15. Polajžer, B.; Ritonja, J.; Štumberger, G.; Dolinar, D.; Lecointe, J.P. Decentralized PI/PD position control for active magnetic bearings. Electr. Eng. 2006, 89, 53-59. [CrossRef]

16. Wei, C.; Söffker, D. Optimization strategy for PID-controller design of AMB rotor systems. IEEE Trans. Control Syst. Technol. 2015, 24, 788-803. [CrossRef]

17. Chen, K.Y.; Tung, P.C.; Tsai, M.T.; Fan, Y.H. A self-tuning fuzzy PID-type controller design for unbalance compensation in an active magnetic bearing. Expert Syst. Appl. 2009, 36, 8560-8570. [CrossRef]

18. Chang, L.Y.; Chen, H.C. Tuning of fractional PID controllers using adaptive genetic algorithm for active magnetic bearing system. WSEAS Trans. Syst 2009, 8, 158-167.

19. Ellis, G. Control System Design Guide: Using Your Computer to Understand and Diagnose Feedback Controllers; Butterworth-Heinemann: Oxford, UK, 2012.

20. Nevaranta, N.; Jaatinen, P.; Vuojolainen, J.; Sillanpää, T.; Pyrhönen, O. Adaptive MIMO pole placement control for commissioning of a rotor system with active magnetic bearings. Mechatronics 2020,65, 102313. [CrossRef]

21. Geng, X.; Zhu, C. Sliding Mode Control Based on Linear Quadratic Regulator for an Active Magnetic Bearing Flexible Rotor Virtual Collocated System. In Proceedings of the 2019 22nd International Conference on Electrical Machines and Systems (ICEMS), Harbin, China, 11-14 Augest 2019; pp. 1-5.

22. Cole, M.O.; Chamroon, C.; Keogh, P.S. H-infinity controller design for active magnetic bearings considering nonlinear vibrational rotordynamics. Mech. Eng. J. 2017, 4. [CrossRef]

23. Saha, S.; Banerjee, A.; Amrr, S.M.; Nabi, M. Pseudospectral method-based optimal control for a nonlinear five degree of freedom active magnetic bearing system. Trans. Inst. Meas. Control 2021, 43, 1668-1679. [CrossRef]

24. Utkin, V.; Guldner, J.; Shi, J. Sliding Mode Control in Electro-Mechanical Systems; CRC press: Boca Raton, FL, USA, 2009.

25. Edwards, C.; Spurgeon, S. Sliding Mode Control: Theory and Applications; CRC press: Boca Raton, FL, USA, 1998.

26. Jang, M.J.; Chen, C.L.; Tsao, Y.M. Sliding mode control for active magnetic bearing system with flexible rotor. J. Franklin Inst. 2005, 342, 401-419. [CrossRef]

27. Nicola, M.; Nicola, C.I. Sensorless fractional order control of PMSM based on synergetic and sliding mode controllers. Electronics 2020, 9, 1494. [CrossRef]

28. Kang, M.S.; Lyou, J.; Lee, J.K. Sliding mode control for an active magnetic bearing system subject to base motion. Mechatronics 2010, 20, 171-178. [CrossRef] 
29. Lin, F.J.; Chen, S.Y.; Huang, M.S. Intelligent double integral sliding-mode control for five-degree-of-freedom active magnetic bearing system. IET Control Theory Appl. 2011, 5, 1287-1303. [CrossRef]

30. Yao, X.; Chen, Z. Sliding mode control with deep learning method for rotor trajectory control of active magnetic bearing system. Trans. Inst. Meas. Control 2019, 41, 1383-1394. [CrossRef]

31. Shtessel, Y.; Edwards, C.; Fridman, L.; Levant, A. Sliding Mode Control and Observation; Springer: Cham, Switzerland, 2014.

32. $\mathrm{Xu}, \mathrm{Q}$. Precision motion control of piezoelectric nanopositioning stage with chattering-free adaptive sliding mode control. IEEE Trans. Autom. Sci. Eng. 2016, 14, 238-248. [CrossRef]

33. Bartolini, G.; Fridman, L.; Pisano, A.; Usai, E. Modern Sliding Mode Control Theory: New Perspectives and Applications; Springer: Cham, Switzerland, 2008.

34. Kandil, M.S.; Dubois, M.R.; Bakay, L.S.; Trovao, J.P.F. Application of Second-Order Sliding-Mode Concepts to Active Magnetic Bearings. IEEE Trans. Ind. Electron. 2017, 65, 855-864. [CrossRef]

35. Levant, A. Principles of 2-sliding mode design. Automatica 2007, 43, 576-586. [CrossRef]

36. Boiko, I.M. Chattering in sliding mode control systems with boundary layer approximation of discontinuous control. Int. J. Syst. Sci. 2013, 44, 1126-1133. [CrossRef]

37. Utkin, V. Discussion aspects of high-order sliding mode control. IEEE Trans. Autom. Control 2015, 61, 829-833. [CrossRef]

38. Amrr, S.M.; Nabi, M. Finite-time fault tolerant attitude tracking control of spacecraft using robust nonlinear disturbance observer with anti-unwinding approach. Adv. Space Res. 2020, 66, 1659-1671. [CrossRef]

39. Giap, V.N.; Huang, S.C.; Nguyen, Q.D.; Trinh, X.T. Time Varying Disturbance Observer Based on Sliding Mode Control for Active Magnetic Bearing System. In Proceedings of the 2nd Annual International Conference on Material, Machines and Methods for Sustainable Development (MMMS2020), Nha Trang, Vietnam, 12-15 November 2020; pp. 929-935.

40. Amrr, S.M.; Banerjee, A.; Nabi, M. Time-Energy Efficient Finite Time Attitude Tracking Control of Spacecraft Using Disturbance Observer. IFAC-PapersOnLine 2020, 53, 5964-5969. [CrossRef]

41. Levant, A. Homogeneity approach to high-order sliding mode design. Automatica 2005, 41, 823-830. [CrossRef]

42. Davila, J.; Fridman, L.; Levant, A. Second-order sliding-mode observer for mechanical systems. IEEE Trans. Autom. Control 2005, 50, 1785-1789. [CrossRef]

43. Slotine, J.-J.; Li, W. Applied Nonlinear Control; Prentice Hall: Hoboken, NJ, USA, 1991.

44. Vo, A.T.; Kang, H.J. A chattering-free, adaptive, robust tracking control scheme for nonlinear systems with uncertain dynamics. IEEE Access 2019, 7, 10457-10466. [CrossRef]

45. Yang, J.; Li, S.; Yu, X. Sliding-mode control for systems with mismatched uncertainties via a disturbance observer. IEEE Trans. Ind. Electron. 2012, 60, 160-169. [CrossRef]

46. Amrr, S.M.; Nabi, M.; Tiwari, P.M. A fault-tolerant attitude tracking control of spacecraft using an anti-unwinding robust nonlinear disturbance observer. Proc. Inst. Mech. Eng. Part J. Aerosp. Eng. 2019, 233, 6005-6018. [CrossRef]

47. Levant, A. Higher-order sliding modes, differentiation and output-feedback control. Int. J. Control 2003, 76, 924-941. [CrossRef]

48. Alanis, A.Y.; Munoz-Gomez, G.; Rivera, J. Nested High Order Sliding Mode Controller with Back-EMF Sliding Mode Observer for a Brushless Direct Current Motor. Electronics 2020, 9, 1041. [CrossRef]

49. Merabet, A. Cascade second order sliding mode control for permanent magnet synchronous motor drive. Electronics 2019, 8, 1508. [CrossRef]

50. Huynh, V.V.; Hoang, B.D. Second order sliding mode control design for active magnetic bearing system. In AETA 2015: Recent Advances in Electrical Engineering and Related Sciences; Springer: Cham, Switzerland, 2016; pp. 519-529.

51. Chen, S.Y.; Lin, F.J. Robust nonsingular terminal sliding-mode control for nonlinear magnetic bearing system. IEEE Trans. Control Syst. Technol. 2010, 19, 636-643. [CrossRef]

52. Chiang, H.K.; Fang, C.C.; Lin, W.B.; Chen, G.W. Second-order sliding mode control for a magnetic levitation system. In Proceedings of the 2011 8th Asian Control Conference (ASCC), Kaohsiung, Taiwan, 15-18 May 2011; pp. 602-607.

53. Jain, S.; Mishra, J.P.; Talange, D. A robust control approach for magnetic levitation system based on super-twisting algorithm. In Proceedings of the 2015 10th Asian Control Conference (ASCC), Kota Kinabalu, Malaysia, 31 May-3 June 2015; pp. 1-6.

54. Wang, X.; Zhang, Y.; Gao, P. Design and Analysis of Second-Order Sliding Mode Controller for Active Magnetic Bearing. Energies 2020, 13, 5965. [CrossRef]

55. Saha, S.; Amrr, S.M.; Nabi, M. Adaptive Second Order Sliding Mode Control for the Regulation of Active Magnetic Bearing. IFAC-PapersOnLine 2020, 53, 1-6. [CrossRef]

56. Maslen, E.H.; Schweitzer, G. Magnetic Bearings: Theory, Design, and Application to Rotating Machinery; Springer: Cham, Switzerland, 2009.

57. Sivrioglu, S. Adaptive backstepping for switching control active magnetic bearing system with vibrating base. IET Control Theory Appl. 2007, 1, 1054-1059. [CrossRef]

58. Abooee, A.; Arefi, M.M. Robust finite-time stabilizers for five-degree-of-freedom active magnetic bearing system. J. Franklin Inst. 2019, 356, 80-102. [CrossRef]

59. Lin, F.; Chen, S.; Huang, M. Tracking control of thrust active magnetic bearing system via hermite polynomial-based recurrent neural network. IET Electr. Power Appl. 2010, 4, 701-714. [CrossRef]

60. Saidi, A.S. Investigation of Structural Voltage Stability in Tunisian Distribution Networks Integrating Large-Scale Solar Photovoltaic Power Plant. Int. J. Bifurcation Chaos 2020, 30, 2050259. [CrossRef] 
61. Bhat, S.P.; Bernstein, D.S. Finite-time stability of homogeneous systems. In Proceedings of the 1997 American Control Conference, Albuquerque, NM, USA, 6 June 1997; Volume 4, pp. 2513-2514.

62. Bhat, S.; Bernstein, D.S. Finite-time stability of continuous autonomous systems. SIAM J. Control Optim. 2000, 38, 751-766. [CrossRef]

63. Mondal, S.; Mahanta, C. Adaptive integral higher order sliding mode controller for uncertain systems. J. Control Theory Appl. 2013, 11, 61-68. [CrossRef]

64. Taleb, M.; Plestan, F.; Bououlid, B. An adaptive solution for robust control based on integral high-order sliding mode concept. Int. J. Robust Nonlinear Control 2015, 25, 1201-1213. [CrossRef]

65. Bhat, S.P.; Bernstein, D.S. Geometric homogeneity with applications to finite-time stability. Math. Control Signals Syst. 2005, 17, 101-127. [CrossRef] 